This paper has to be cited as: : D. Infante, D. Di Martire, P. Confuorto, S. Tessitore, R. Tòmas, D. Calcaterra, et al., "Assessment of building behavior in slow-moving landslide-affected areas through DInSAR data and structural analysis," Engineering Structures, vol. 199, p. 109638, 2019/11/15/ 2019. The final publication is available at Elsevier via:

\title{
Assessment of building behavior in slow-moving landslide-affected areas through DInSAR data and structural analysis
}

\author{
Infante Donato ${ }^{1}$, Di Martire Diego ${ }^{1}$, Confuorto Pierluigi ${ }^{1}$, Tessitore Serena ${ }^{1}$, Tómas Roberto ${ }^{2}$, \\ Calcaterra Domenico ${ }^{1}$, Ramondini Massimo ${ }^{3}$
}

Donato Infante ${ }^{1}$, infantedonato@ hotmail.it

Diego Di Martire ${ }^{1}$, diego.dimartire@unina.it, via Cintia 21, Complesso Universitario Monte Sant'Angelo, 80126, Naples, Italy, +390812538135

Pierluigi Confuorto ${ }^{1}$, pierluigi.confuorto@unina.it

Serena Tessitore ${ }^{1}$, tessitoreserena@gmail.com

Roberto Tomàs², roberto.tomas@ua.es

Domenico Calcaterra ${ }^{1}$, domenico.calcaterra@unina.it

Massimo Ramondini ${ }^{3}$, ramondin@unina.it

${ }^{1}$ Department of Earth Sciences, Environment and Resources, University of Naples "Federico II"

${ }^{2}$ Department of Civil Engineering, University of Alicante

${ }^{3}$ Department of Civil Engineering, Architectural and Environment, University of Naples "Federico II"

The Authors declare no conflicts of interests

\begin{abstract}
Slow-moving landslides are a natural hazard which affects wide areas in the world and often are cause of significant damage to structures and infrastructures. Analysis of landslide evolution and of their interaction with existing man-made structures plays a key role in risk prevention and mitigation activities. To this purpose, a considerable interest towards innovative approaches has grown among the scientific community and land management institutions. In this work, Synthetic Aperture Radar data acquired by $\mathrm{C}$-band and X-band sensors, combined with numerical analyses, have been successfully applied as a tool to detect spatial and temporal landslide-induced effects, in terms of deformations and structural behavior of a building affected by ground instability. Such approach has
\end{abstract}


been applied to Moio della Civitella urban settlement (Salerno province, Italy), whose whole territory is interested by several slow-moving landslides. In detail, performance of a masonry building aggregate and the efficacy of restoration works have been investigated through an integrated assessment of displacement time-series pre- and post-repair intervention, and structural analysis performed with numerical code.

Historical DInSAR data have permitted firstly the interpretation of building displacement time-series corresponding to pre- and post-works configurations; subsequently, the analysis of interpolated interferometric products has allowed to define gradient maps of vertical and horizontal displacements and to identify part of aggregate which can suffer a greater susceptibility to damage as a consequence of deformation gradients. Finally, the comparison of satellite and numerical data showed a substantial agreement with local failures and damage surveyed, thus confirming the capability of DInSAR technique to investigate building performance where no in situ displacement measurements were available.

Keywords: slow-moving landslides, building damage, displacement monitoring, DInSAR

\section{Introduction}

The occurrence of landslides in urban areas can cause a serious threat to facilities, structures and infrastructures. In Europe and in Italy in particular, where half a million active landslides exist, mass movements represent an important cause of damage $[1,2]$.

Existing buildings are sensitive to ground movements caused by slow-moving landslides: when buildings are located within a landslide area, the interaction is of "static" type, generating rigid rotations or angular distortions as a result of differential displacements.

Evaluation of building structural performance, meant as assessment of damage conditions, plays a key role in risk prevention and mitigation activities. In fact, spatial and temporal analysis both of ground deformation and of building damage degree represents a useful tool to understand landslide 
evolution and structures behavior. This approach can be suitable to evaluate how the elements at risk in a landslide-affected area may change with time, contributing to the risk assessment, which is very important for decision making by Civil Protection Authorities [3].

Different approaches $[4,5,6,7,8]$ to investigate performance of building affected by ground instability phenomena have been described in literature. However, each approach is characterized by its own peculiarity, exhibiting differences in their respective final results. Indeed, at present no only one standard methodology exists. Based on the scale of analysis and the availability and quality of input data, the vulnerability analysis, defined as assessment of potential physical losses arising from landslide phenomena, can be carried out and expressed using vulnerability matrices and indices-based approach, vulnerability domains, fragility curves.

Vulnerability matrices and indices-based approaches can estimate the expected degree of loss to a given building, by using a qualitative measure of consequences or a numeric rating scale ranging from 0 (no loss) to 1 (total loss).

Vulnerability domains and fragility curves approaches, instead, are used to provide quantitative assessment of building physical vulnerability. Fragility curves, in particular, are a useful tool to assess the conditional probability of reaching or exceeding a certain level of damage severity as a function of the landslide characteristics; thus, they express the vulnerability of buildings in probabilistic terms, incorporating also uncertainties related.

These approaches are often the most practical when a large amount of empirical data is available.

The approach considered in this work also is based on a logical structure which takes into account landslide intensity and structural characterization of the exposed elements. The main novelty of proposed methodology is attributable to the combined use of remote sensing satellite data and numerical structural analyses performed on computational model of a single building.

Nowadays, slow-moving ground deformations can be easily detected and monitored using satellite radar techniques, integrated with conventional geomorphological field surveys and in situ measurements. In particular, during the last decade, Differential SAR Interferometry (DInSAR) has 
been successfully applied as a remote-sensing tool in several analyses aimed to monitoring the impacts of ground movements in urban areas $[9,10,11,12,13,14,15]$.

The combined use of non-operating historical C-band satellites and operating X-band Synthetic Aperture Radar sensors of new generation allows a multi-spatial and temporal detection of landslide effects, at relatively reasonable costs, thanks to its accuracy, non-invasiveness and long-term temporal coverage. European Space Agency (ESA) C-band satellites (e.g. ENVISAT ASAR) provide long historical archives of motion rates and time series, covering wide areas at medium spatial resolution. On the other hand, X-band data, with higher spatial and temporal resolution, allow a more detailed investigation at the scale of a single building distortions $[16,17,18]$.

In particular, the launch of SAR sensors which operate at $3 \mathrm{~cm}$ wavelength in X-band, i.e., TerraSAR$\mathrm{X}$ and COSMO-SkyMed, with higher spatial resolution $(3 \times 3 \mathrm{~m})$ and reduced revisiting time (4-16 days) compared to the previous operating C-band satellites, has enhanced DInSAR capability for displacement monitoring. X-band SAR images make the number of retrieved targets higher by a factor of approximately 100-200, compared to medium resolution data [19], allowing to investigate settlement profiles along building façades, maximum distortions occurred and prevalent direction of movements.

Instead, the characterization of exposed elements requires to define building construction properties accomplished with an accuracy level which depends on diagnosis criteria. Therefore, to implement building computational model in a numerical software, geometrical data, types of structure, typology of foundation and mechanical properties of structural materials, have to be assessed.

In this work, we propose an integrated use of displacement time-series recorded by C- and X-band satellites, and of structural analyses performed in a numerical code, to assess the performance of buildings to ground movements as well as the efficacy of restoration works interesting part of building aggregates. 
Such study permits to evaluate building deformations in pre- and post-intervention stages and subsequently to achieve a preliminary assessment of the relationship between the landslides intensity and damage severity exhibited by each involved building.

The paper is organized as follows: the proposed approach is described in detail in Section 2; Section 3 introduces the study area used to illustrate the methodology as well as the used InSAR datasets and the available information of the building survey; to a comprehensive interpretation and discussion of the results from the test site are described in Section 4; finally, Section 5 summarizes the main conclusions of the paper.

\section{Methodology}

In the present paper a general approach for the assessment of the building performance to actions resulting from slope instabilities is provided.

Aimed to investigate the relationship between cause (displacements induced by landslide) and effect (distortions and damage to existing buildings), such methodology is developed according to the flowchart shown in Figure 1.

As first step, a preliminary characterization of subsoil geological setting and of landslides is required (green box). In particular the combined study of geological and geomorphological maps allows to evaluate the influence of geological properties on the spatial distribution of mass movements and to identify the predisposing factors of ground displacements.

Subsequently, behavior of different buildings affected by ground movements and, in particular, the efficacy of restoration works can be assessed following two approaches:

-analysis of displacements time-series pre- and post-repair intervention obtained through Differential Synthetic Aperture Radar Interferometry (DInSAR) (orange box);

-structural analyses performed in a numerical code of computational models corresponding to original (pre- intervention) and current (post-intervention) configurations (red box). 


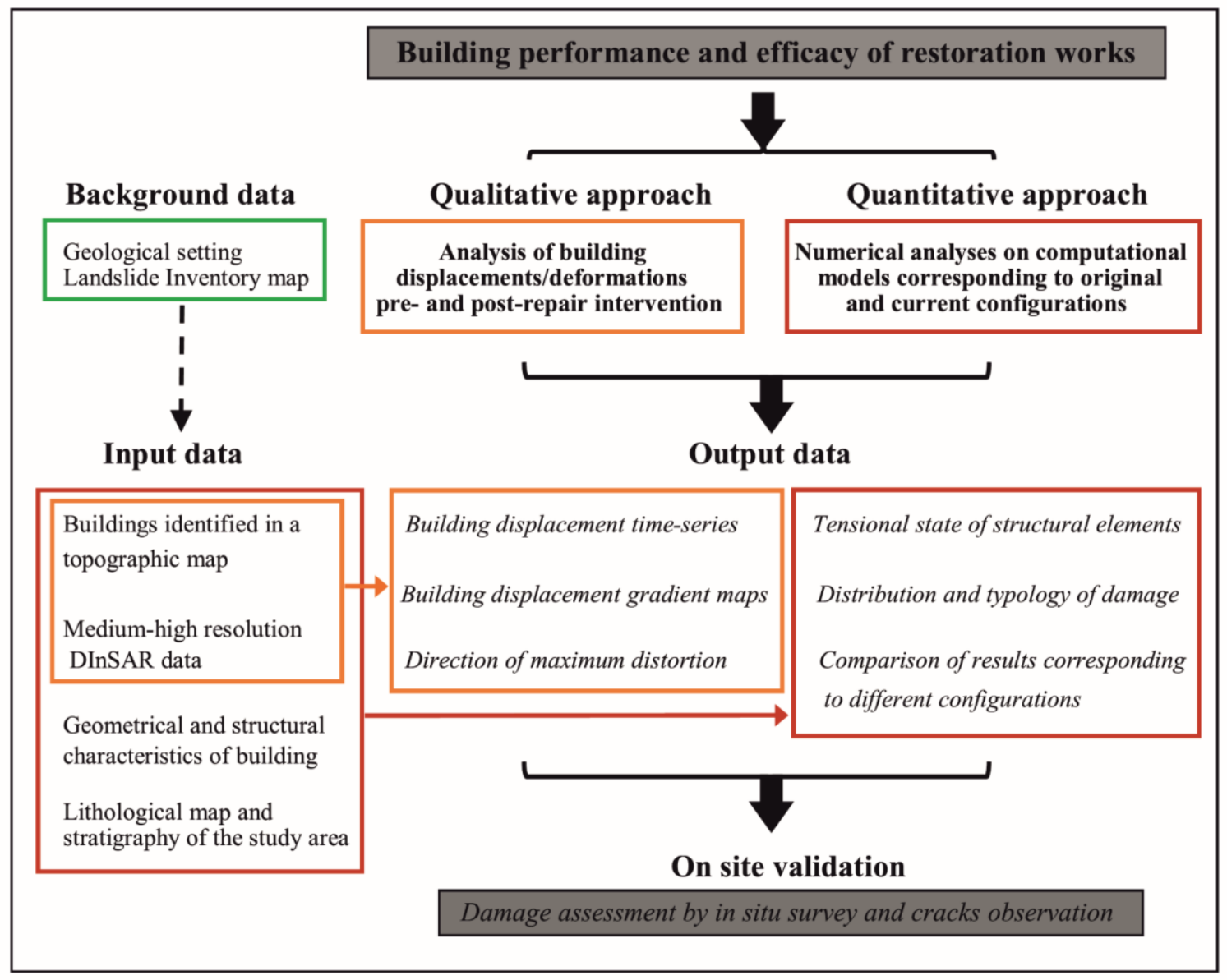

Figure 1. Methodology flowchart: approaches, input and output data.

As regards the analysis of displacement time series before and after the intervention, it is important to highlight that building deformations can be achieved by means of conventional (instrumental or topographical surveys) and Differential Interferometric Synthetic Aperture Radar (DInSAR) techniques. The first ones can give useful information on the phenomenon development, resulting highly expensive if a great amount of measurements is required [20]. On the other hand, DInSAR techniques $[21,22,23]$ provide deformation velocity maps and time series (TS) for reliable pixels exhibiting a good phase quality, having become a consolidated technique for deformation measurements, both of ground surface and of structures.

Such approach, however, does not take into account structural behavior of buildings: for this reason, occurrence and location of cracks and local failures cannot be investigated. Aimed to overcome these constraints, a soil-structure model can be created in a numerical software. 
Non-linear static analyses performed on a building computational models, applying progressively displacement profiles measured by DInSAR data, permit to detect temporal and spatial evolution of damage. Furthermore, efficacy of remedial works can be assessed by analyzing a difference of behavior among the two models corresponding to configurations pre- and post-intervention.

In this work, dealing with masonry structures, an ad hoc algorithm is required capable of reproducing the non-linear behavior of masonry structures under static and seismic loadings, compared to ordinary concrete and steel buildings. Moreover, 3DMacro computer code [24], developing an original modelling approach and providing reliable numerical simulations, has been used.

Finally, validation of results can be obtained by comparison among results provided by DInSAR and structural analyses on computational model and real damage observed by in situ survey (grey box). In the following paragraphs, a detailed overview of the above-mentioned approaches, input and output data, will be discussed.

\subsection{DInSAR analysis}

In this work, building deformations before and after the restoration of the foundation have been recorded through the processing of SAR images by Coherence Pixels Technique [25], a processing chain able to extract the deformation evolution during long time spans from a stack of differential interferograms.

Figure 2 shows the progressive steps of multi-level analysis of satellite data to assess performance and deformations of buildings affected by slow-moving landslide.

Satellite radar images acquired along ascending and descending tracks represent input data (green box). Interferometric products which can be obtained by processing are defined in red boxes, the final outputs are shown in orange boxes, while the validation process of the results are reported in grey boxes.

Mean yearly velocities and cumulative displacement provided by interferometric products are measured along the satellite Line of Sight direction $(\operatorname{LoS})$ on a discrete number of points, called 
scatterers. By analyzing the displacement time series of targets identified on each building by ENVISAT ASAR and COSMO-SkyMed satellites, a possible change of behavior in the displacement trend before and after the date of repair can be detected.

Since these measurements are characterized by a discrete point-sampling, a geostatistical interpolation of targets cumulative displacement is needed to obtain a continuous displacement map, thus, to estimate ground motion displacements occurring in the monitoring period, even where no scatterers are available. Following this way, the Inverse Distance Weighted (IDW) interpolation method was used to create a continuous displacement-surface map from the sample set of scatterer data. Resolution of the IDW interpolation cell has to be set according to the resolution of the spaceborne radar images: for instance, the pixel size of the resulting surface could be set as $3 \times 3 \mathrm{~m}$ if exploiting high resolution X-band data (e.g., COSMO-SkyMed satellite) or equal to $20 \times 20 \mathrm{~m}$ if Cband satellites (e.g. ENVISAT ASAR) are used. Furthermore, the high density of points of measurement regarded on buildings, allows to reduce the level of uncertainties.

As a result, a displacement value can be assigned to each pixel centroid of the interpolated surface, thus obtaining a regular grid of distributed rates.

Furthermore, availability of images acquired both along "ascending" and "descending" tracks allows to define vertical and horizontal components of movements [26, 27]. Considering these displacements, the interpolated maps have been used to estimate the gradient of displacements affecting building masonry walls, according to the definition provided by Burland and Wroth [28] and to identify the direction along which maximum differential movements have occurred [29]. It is important to highlight that, dealing with long surficial masonry stripes as foundation, displacements at foundation level have been fixed equal to them obtained to ground level. Such analysis represents an important step to define building conditions. The change in displacement-value, in fact, describes a condition for which a part of a building foundation is moving at a different rate from other portions of the foundation and, commonly, buildings affected by ground surface differential movements can 
suffer anisotropic stresses and, as a consequence, a greater susceptibility to damage. A validation process of these results with damage occurred on building façades is required (grey box).

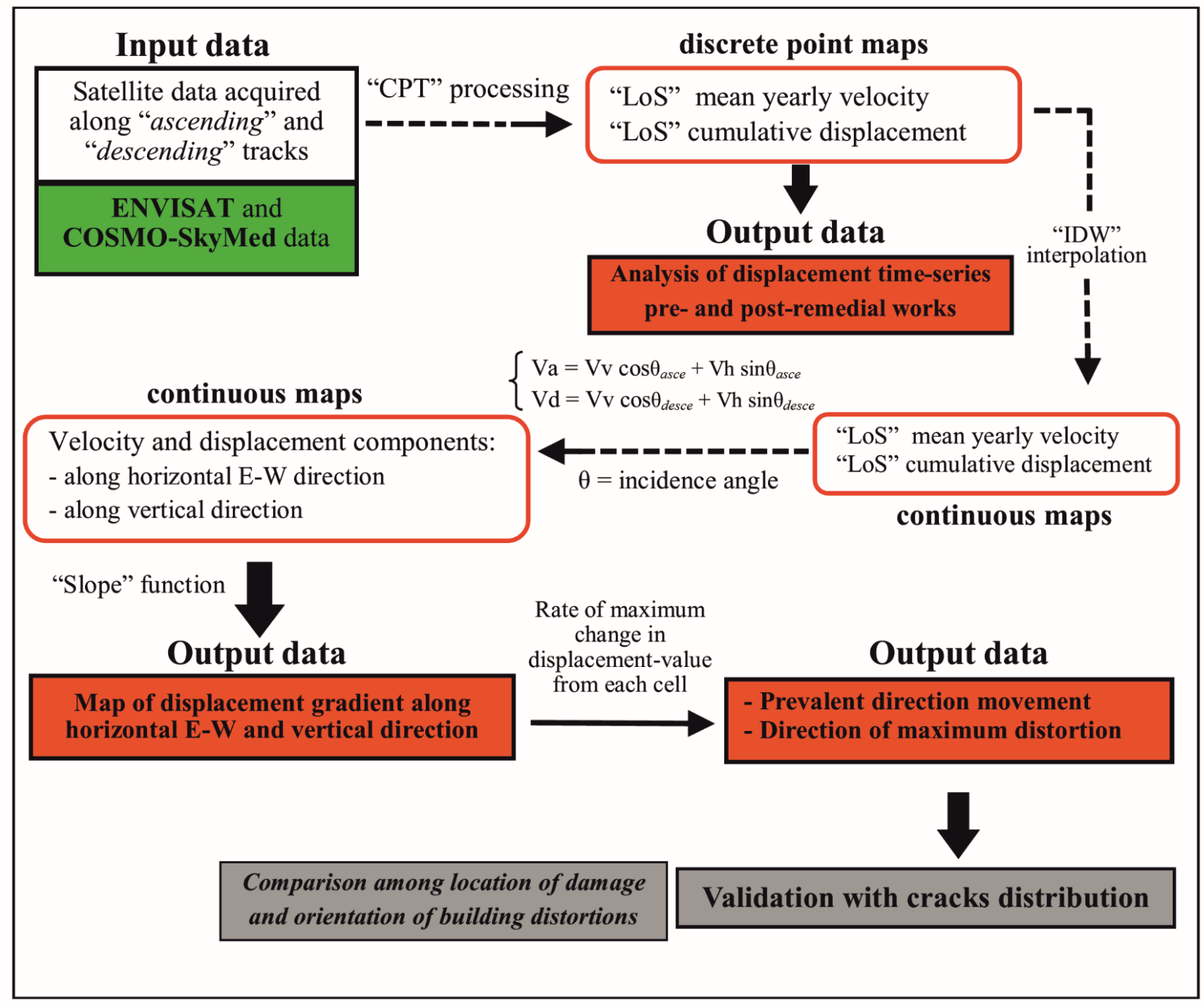

Figure 2. DInSAR analysis for the detection of building performance. Note that $\theta$ asce and $\theta$ desce are the ascending and descending incidence angles, respectively. Input data are shown in green box, interferometric products in red boxes, final output results in orange boxes, validation process in grey boxes.

\subsection{The macro-elements approach for the assessment of behaviour of masonry buildings}

As mentioned in section 1, the analysis of building deformations does not take into account its structural properties, not allowing to investigate in detail the occurrence of cracks due to ground movements. 
Aimed to assess different performance of structures in pre- and post-remedial work phases, quantitative analyses have been performed for a selected building, according to the flowchart shown in Figure 3.

Input data have been defined in green boxes. Through a detailed geometrical and a structural survey, a 3D computational model of the selected building, corresponding to the pre- and post-intervention configurations, have been implemented in a numerical code. Subsequently, vertical and horizontal displacement profiles measured by DInSAR data in the considered period at ground level along building façades have been progressively imposed to the foundations of both models: each interface of foundation stripes exhibits three degrees-of-freedom, associated to the in-plane rigid body motion, thus DInSAR displacements have been applied as external loads corresponding to fixed values of these degrees-of-freedom. Finally, non-linear static analyses have been performed.

In detail, to assess the global performance of the selected masonry building aggregate, the number of masonry panels with elastic behavior and the number of yielded and fissured elements have been evaluated (yellow box). The comparison of the results obtained on computational models affected by the same displacement profiles, allow to highlight a different behavior between both configurations (orange box). Furthermore, such analysis allows to investigate tensional state of each panel and also identify the portions of the masonry walls where the main collapse mechanisms and damage occur. In the present work, dealing with masonry structures, an ad hoc algorithm, capable of reproducing the non-linear behavior of masonry and providing reliable numerical simulations, is required. More specifically, 3DMacro computer code [24], has been used, implementing a more original modelling approach for the simulation of the non-linear behavior of masonry structures under static and seismic loadings, than those usually used for ordinary concrete and steel buildings modelling. The main simplified models for the simulation of masonry walls in the literature are the so called 'equivalent frame models' where a masonry panel is simulated with an equivalent beam which can interact with other elements at its ends $[28,30]$. On the contrary, the proposed modelling approach is based on the concept of macro-element discretization of masonry panels [31] and has been conceived 
with the aim of capturing the non-linear behavior of an entire building by means of an assemblage of several discrete elements, as shown in Figure 3.

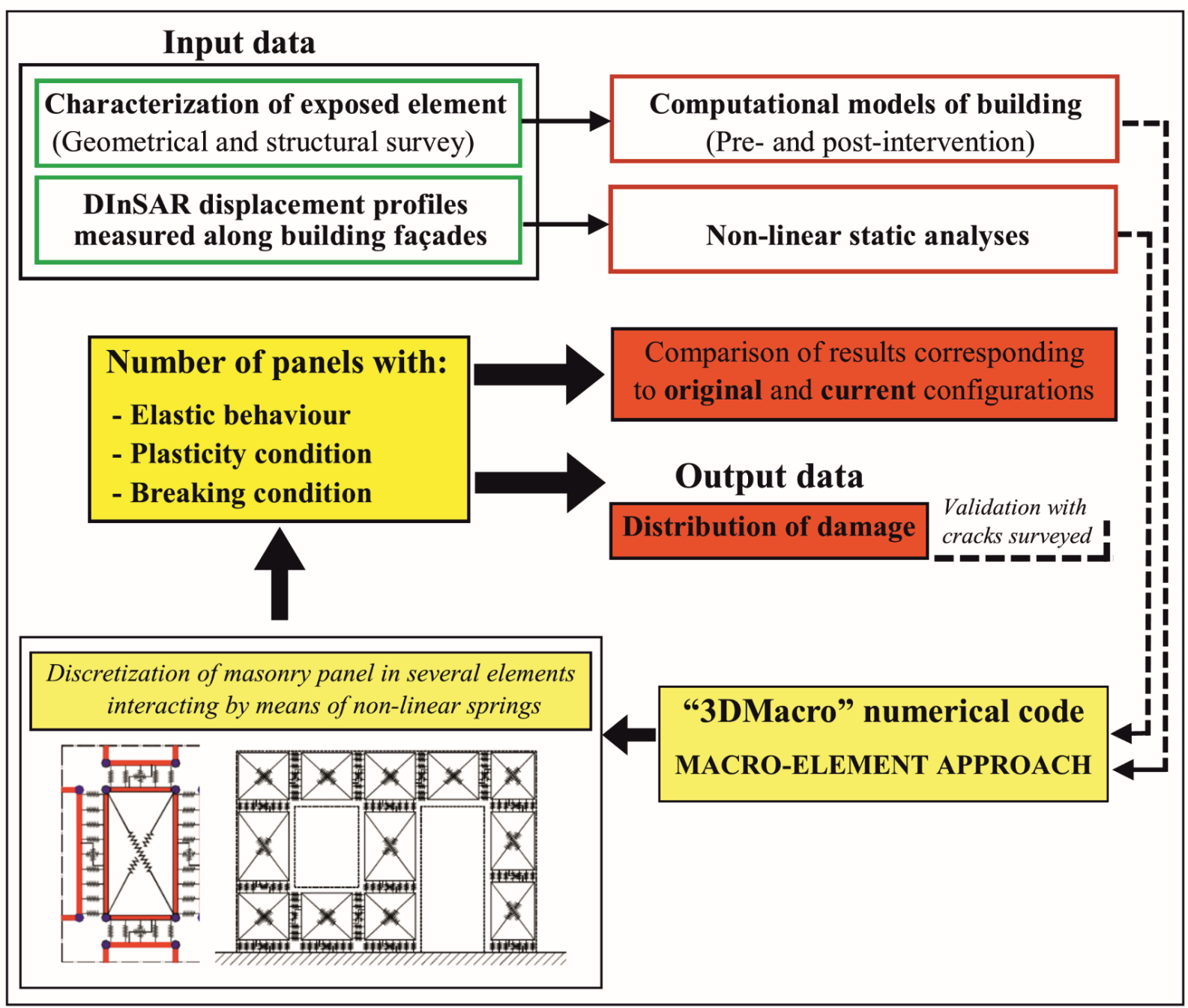

Figure 3. Numerical approach to investigate building performance by structural analyses.

It is worth to notice that the model can also be refined by using a higher number of elements in order to better describe the kinematics of the masonry wall. Such elements are characterized by a simple and easy-comprehensive mechanical scheme constituted by an articulated quadrangle with rigid edges connected by four hinges and two non-linear diagonal springs.

Each element exhibits three degrees-of-freedom, associated to the in-plane rigid body motion, plus a further degree-of-freedom needed to describe the in-plane deformability. Hence the total degrees of freedom of a n panels structural scheme are $4 n$. 
The adopted model has the advantage to allow the interaction of the element along the four sides, by means of a discrete distribution of the non-linear springs, denoted as interface. Each interface is constituted by $n$ non-linear orthogonal springs, perpendicular to the panel side, and an additional longitudinal spring, parallel to the panel edge.

According to [32], since the masonry is considered as a homogeneous media, the global behavior can be ascribed to its flexural and shearing characteristics.

The flexural behavior is simulated by the transversal springs of the interfaces which connect the panel with other elements and/or external supports. Each spring has been calibrated by assuming a nonsymmetric elasto-plastic behavior with limited deformability. A different behavior for rupture in compression and in tension has been provided. In fact, when a spring reaches the limit displacement in compression after the unloading it is totally removed from the model. When a spring attains the limit displacement in tension, it will be no more able to carry tension forces but it can bear compressive loads once the contact between the elements is restored.

The sliding spring has the role of simulating the potential sliding between the two elements connected by the interface. This spring is characterized by a rigid-plastic constitutive law with a Mohr-Coulomb yielding surface.

At last, to simulate the shearing behavior of diagonal springs of the panel, an elasto-plastic constitutive law with a Turnsek \& Cacovic [33] yielding limit depending on the average axial force on the panel, has been adopted.

It is worth to notice that proposed models require a physically characterization of the masonry structure, since all parameters (stiffness, elastic yielding strengths, ultimate displacement) should be calibrated by means of the usually adopted masonry mechanical characteristics.

In spite of its great simplicity, such basic mechanical scheme is able to simulate the main in-plane failures of a portion of masonry wall subjected to horizontal and vertical loads. 


\section{A case study in Moio della Civitella urban settlement}

The above described methodology has been used to investigate the structural performance of an aggregate of masonry buildings placed in Moio della Civitella, a small village located in the Cilento, Vallo di Diano and Alburni National Park, Salerno Province, southern Campania region (Italy) (Figure 4a).

Moio della Civitella territory is composed of two urban settings, Moio and Pellare, situated on the slope of the Civitella mountain (818 m a.s.1.).

In the following section a general overview of geological and geomorphological setting of Moio della Civitella landscape is provided.

\subsection{Geological setting and landslide inventory map}

The study area is one of the most interesting in the Campania region, combining peculiar geological characteristics with valuable natural resources.

The main factors predisposing to instability at Moio della Civitella are the local stratigraphy and morphology.

Moio della Civitella territory is geologically characterized by the presence of the Crete Nere-Saraceno Formation (SCE) [34], a Structurally Complex Formation [35], Cenozoic in age, belonging to the North Calabrian Unit (Figure 4b). The formation is mainly made up of argillites, predominantly of grey colour, with intercalated carbonate and silico-clastic arenites, which often present at the outcrop a weathered horizon whose thickness varies between 0.5 and $5.0 \mathrm{~m}$ [36]. Furthermore, the investigated area is almost continuously overlain by a heterogeneous Quaternary debris cover, about 3 to $25 \mathrm{~m}$ thick, consisting of heterometric arenaceous and conglomeratic blocks within a silty clayey matrix (Figures $4 \mathrm{c}$ and d).

As regards geomorphological conditions, the landscape of Moio della Civitella is characterized by hilly morphologies with relatively low-gradient slopes. 
The existing lithologic, structural, hydrogeologic and geomorphologic settings are among the main factors predisposing to ground instability at Moio della Civitella [37]. The territory is widely affected by erosional and gravitational phenomena. The main slope movements derive from ancient phenomena, which involve large portions or the whole extension, 2-3 $\mathrm{km}$ in length, of the existing slopes. According to the Hydro-geomorphological Setting Plan of South Campania River Basin Authority (2012), about 280 landslides were surveyed within municipal boundaries of Moio della Civitella.
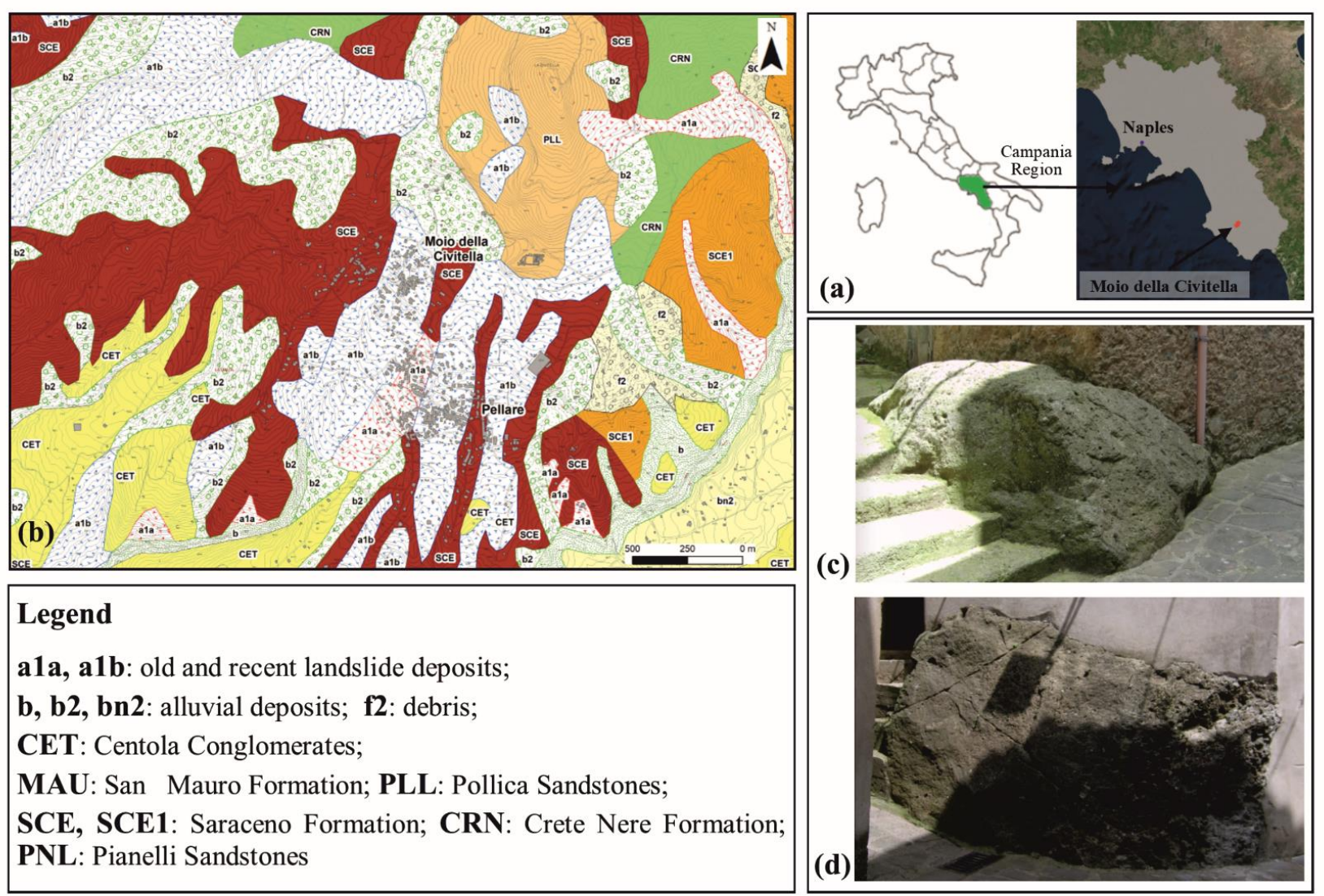

Legend

a1a, a1b: old and recent landslide deposits;

b, b2, bn2: alluvial deposits; f2: debris;

CET: Centola Conglomerates;

MAU: San Mauro Formation; PLL: Pollica Sandstones;

SCE, SCE1: Saraceno Formation; CRN: Crete Nere Formation;

PNL: Pianelli Sandstones

Figure 4. Location (a) and geological sketch map (b) (redrawn from APAT, 2006) of the Moio della Civitella area, and arenaceous and conglomeratic blocks cropping out within the urban settlement $(\mathrm{c}, \mathrm{d})$.

The largest slope movements are mainly flows, rotational/translational landslides and areas affected by diffuse slow movements. Some of these landslides involve the inhabited areas, producing widespread damage to existing buildings, roads, sidewalks and walls. Furthermore, as regards the state of activity, in 2012, most of the landslides were classified as dormant, some of them as active and only seven were identified as inactive. Due to the low seismicity of the area, reactivations are 
usually triggered by intense and continuous rainfall, as demonstrated by recurrent damage occurred to buildings and infrastructures localized within the unstable areas.

The buildings aggregate analyzed in this work is located in the historical center of Moio and it is affected by diffuse slow movements.

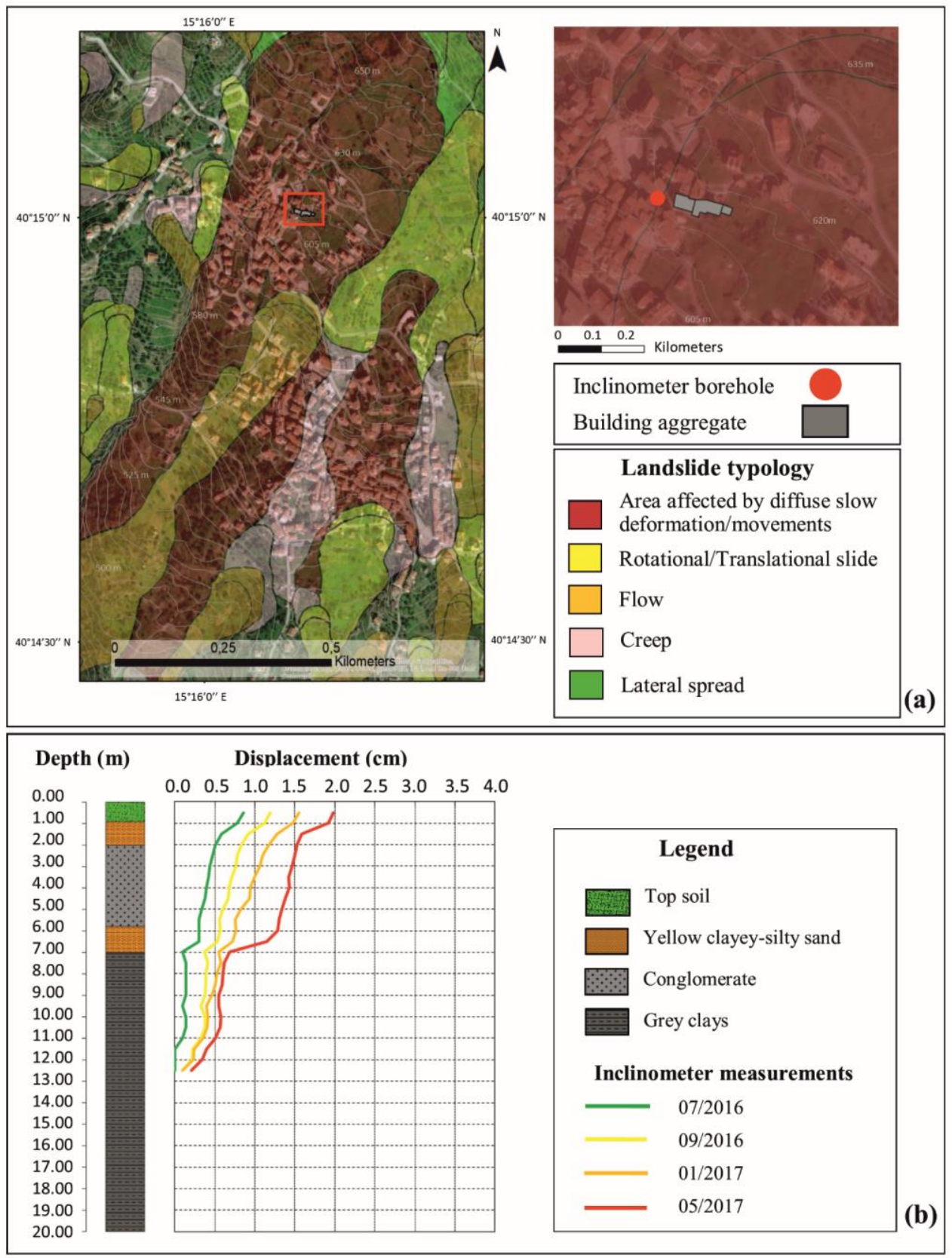

Figure 5. (a) Location of considered buildings aggregate and (b) comparison between stratigraphic column and inclinometer measurements in the period November 2015-May 2017 in a borehole close to the structure.

The integrated analysis of a stratigraphic column and the displacement measurements performed on an inclinometer borehole near the building in the period November 2015-May 2017 has allowed to 
investigate the litho-stratigraphical features and subsequently to locate an active shear surface at a depth of about $7 \mathrm{~m}$, involving top soil and a heterogeneous debris cover of arenaceous and conglomeratic terrains in a matrix of yellow clayey-silty sand.

Moreover, a low rate of displacement $(1.3 \mathrm{~cm} / \mathrm{year}$ at ground surface) has been recorded in the considered time span, as shown in Figure 5.

\subsection{DInSAR data}

To assess displacements both of ground and of existing buildings, due to landslides, ENVISAT and COSMO-SkyMed images have been processed by means of Coherent Pixels Technique [25]. To this aim, the SAR datasets summarized in Table 1 have been used.

Table 1. Summary of SAR datasets used in this study.

\begin{tabular}{|l|c|c|c|}
\hline \multicolumn{1}{|c|}{ Satellite } & Orbit & Period & $\mathbf{N}^{\mathbf{0}}$ of images \\
\hline \multirow{2}{*}{ ENVISAT ASAR } & Ascending & $2002-2010$ & 51 \\
\cline { 2 - 4 } & Descending & $2002-2010$ & 33 \\
\hline \multirow{2}{*}{ COSMO-SkyMed } & Ascending & $2012-2016$ & 76 \\
\cline { 2 - 4 } & Descending & $2012-2016$ & 66 \\
\hline
\end{tabular}

The area of interest selected for the SAR analysis covers about $3 \mathrm{~km} 2$, encompassing the whole urban settlement. Scatterers localized in Moio della Civitella area mainly correspond to man-made features, such as structures and roads. As a first result, for each dataset, the map of mean velocity of displacement along the Line of Sight (LoS) of targets identified on the considered buildings, has been plotted (Figure 6). 


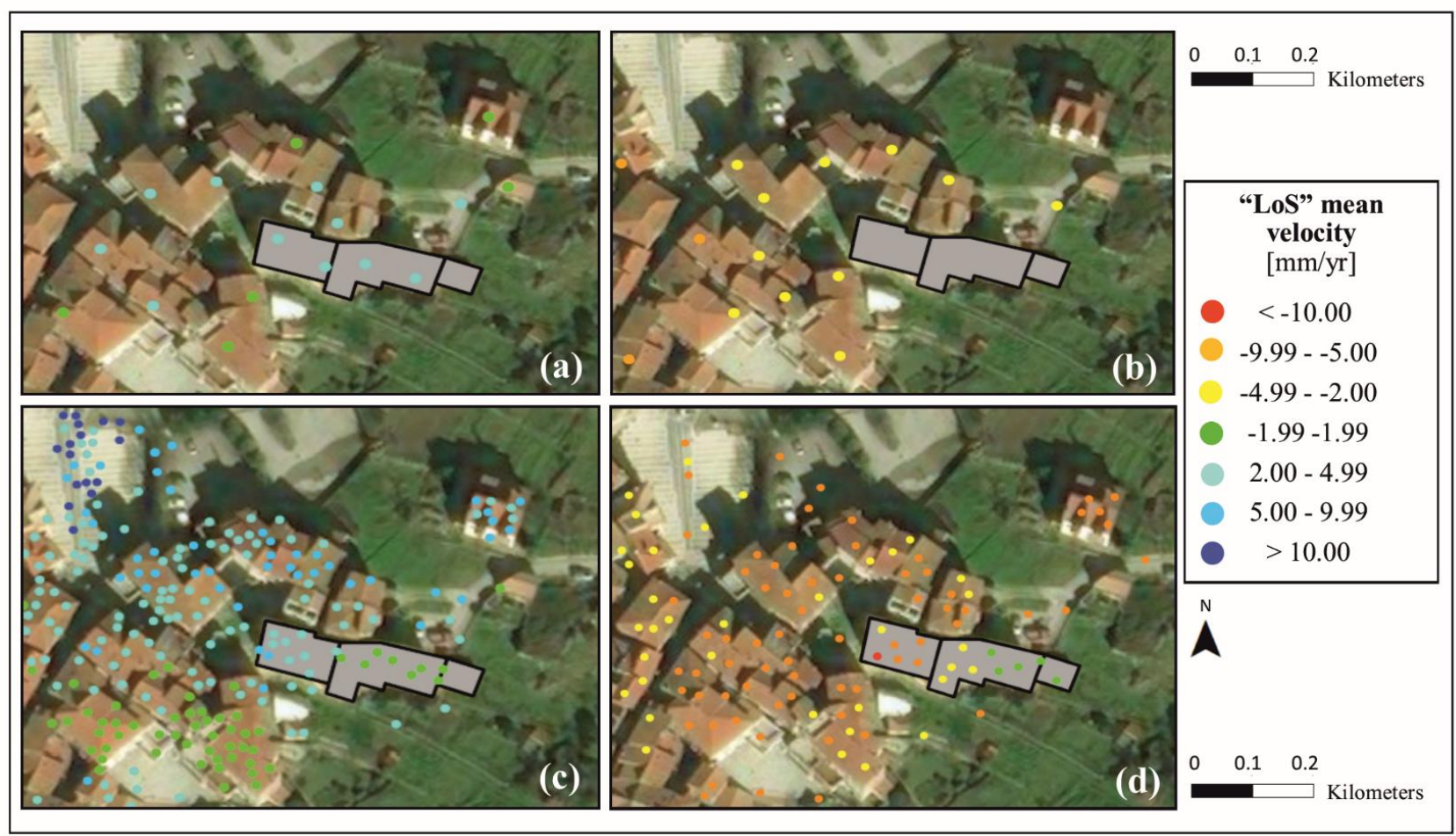

Figure 6. "LoS" displacement velocity map of targets identified on building aggregate by ENVISAT ASAR ascending (a) and descending (b), and COSMO-SkyMed ascending (c) and descending (d) images.

The use of COSMO-SkyMed images strongly increases the number and the density of persistent scatterers in comparison to ENVISAT ASAR images due to its high resolution. In fact, no targets have been detected on the examined structures with ENVISAT descending images (Figure 6b), while more than 10 targets were recognized by COSMO-SkyMed descending images.

Furthermore, it is important to note that for a more detailed assessment of structural performance, displacement profiles of targets identified on building have been taken into account instead of movement rates. In detail, cumulated vertical and horizontal E-W displacements at the end of each year in the period 2012-2016 have been obtained by combining ascending and descending datasets. Such analysis has been possible only for COSMO-SkyMed data, due to the unavailability of persistent scatterers on the considered buildings by ENVISAT ASAR descending products. To this purpose, firstly ascending and descending discretized data have been interpolated through IDW method [38], thus providing continuous "LoS" displacement maps. The cell size of the IDW interpolation has been set at $3 \mathrm{~m}$, according to the $3 \times 3 \mathrm{~m}$ resolution of COSMO-SkyMed products. Subsequently, according to [26] the combination of maps obtained along the two tracks has allowed to detect cumulated 
vertical and horizontal components of movement with millimeter accuracy, as shown in Figure 7. The accuracy of interferometric products has been validated by comparing DInSAR results with conventional data recorded by instrumentations (inclinometers, topographic measure points) installed during field campaigns $[39,40]$.

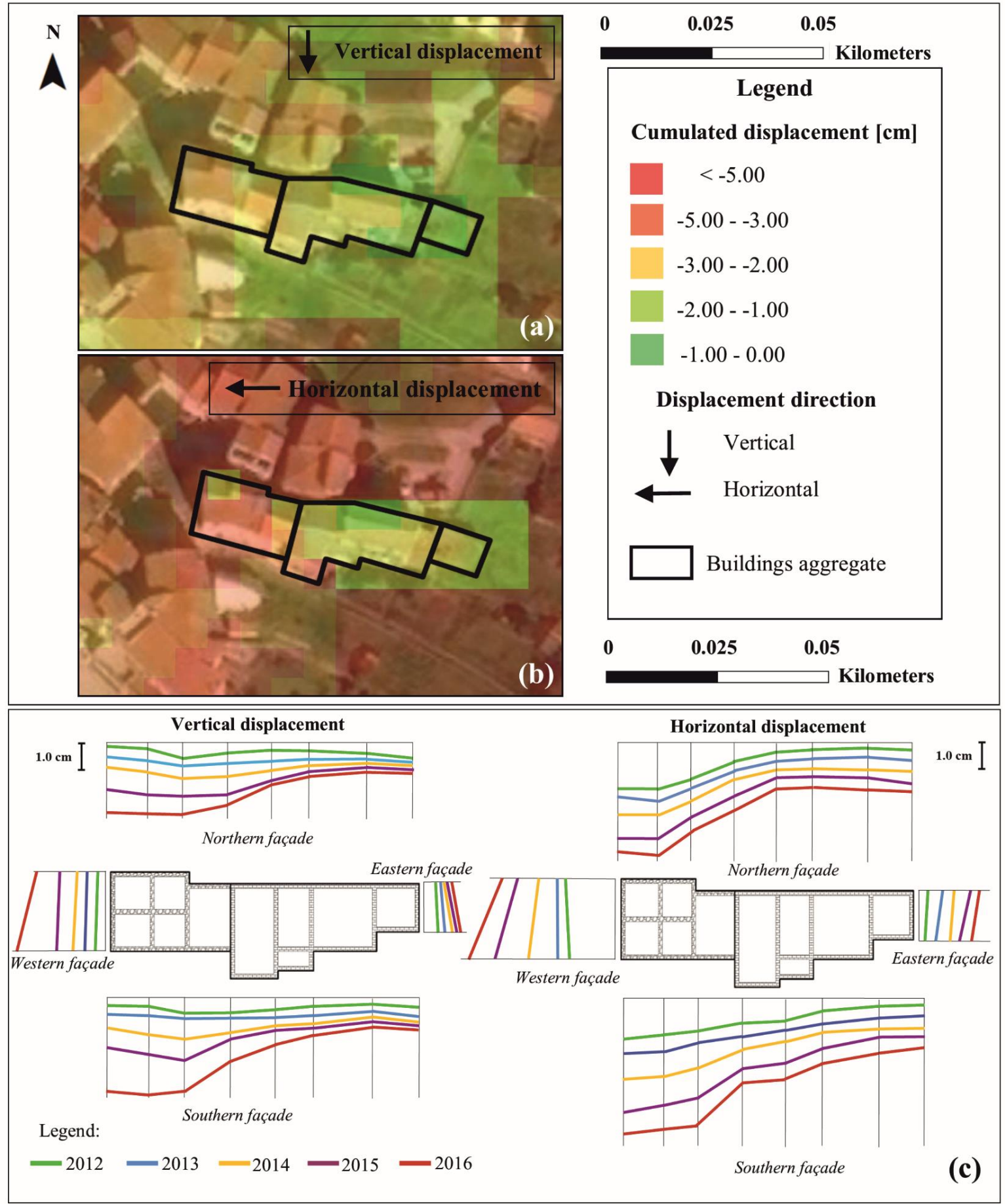

Figure 7. Cumulated displacement maps in the period 2012-2016 along (a) vertical and (b) horizontal directions in the vicinity of the considered aggregate and displacement profiles affecting building foundations at the end of each year (c). 
During the period 2012-2016 DInSAR analysis showed cumulated displacements of the building up to $3 \mathrm{~cm}$ and to $6 \mathrm{~cm}$, along vertical and horizontal direction, respectively, thus highlighting a movement characterized by a horizontal component higher than the vertical one. As discussed below, these displacements have been measured on a part of the aggregate not consolidated by remedial works, while lower movements occurred on the repaired building.

\subsection{Characterization of buildings through available structural data}

As discussed in paragraph 2.2, a numerical approach to assess building performance requires implementing the three-dimensional global model in a computational software. To this aim, geometrical data, types of structures, typology of foundation and mechanical properties of materials, have been assessed through an in-situ survey, performed in February 2017.

In the aggregate, which was built in different periods at the beginning of 20th century, structures are irregular in plan and show vertical irregularities depending on different floor height of adjacent buildings.

Masonry walls, with thickness of $60 \mathrm{~cm}$, were built with natural stones of different type: a part of the aggregate is characterized by elements without any regular shape with different size, while another part shows elements more regular but not perfectly rectangular dressed.

The availability of in situ tests on masonry walls allowed to define the mechanical properties of the building materials: these data have been obtained by consulting results of flat jack testing performed to design remedial works in pre-intervention phase. The values of the non-regular shape and heterometric (e.g. rubble stones, pebbles) and of the roughly worked not perfectly rectangular dressed elements of masonry, adopted for the modelling are summarized in Table 2.

Furthermore, in the original configuration, foundations of all the structures were long masonry stripes (about $1 \mathrm{~m}$ deep as evaluated by survey); for what concerns flat structures (floors), they showed semirigid slab, with wooden beams and a double layer of wooden planks. Subsequently in 2010, a building 
of the aggregate was interested by restoration works: reinforced concrete (r.c.) beams as foundations and beams well connected to rigid reinforced concrete slab as floors were made (Figure 8).

Reinforced concrete (r.c.) beams as foundations, in particular, have a rectangular shape, $100 \mathrm{~cm}$ wide and $50 \mathrm{~cm}$ high, connected to existing masonry foundations. A concrete of strength class $25 / 30$ and B450C steel bars have been used.

Table 2. Mechanical properties of irregular and roughly-worked masonry elements used for modelling the buildings aggregate.

\begin{tabular}{|c|c|c|c|c|c|c|}
\hline Type of masonry & $\begin{array}{c}\text { Young's } \\
\text { Modulus E } \\
{[\mathrm{MPa}]}\end{array}$ & $\begin{array}{c}\text { Shear } \\
\text { Modulus G } \\
{[\mathrm{MPa}]}\end{array}$ & $\begin{array}{c}\text { Compressive } \\
\text { strength sc } \\
{[\mathrm{MPa}]}\end{array}$ & $\begin{array}{c}\text { Tensile } \\
\text { strength st } \\
{[\mathrm{MPa}]}\end{array}$ & $\begin{array}{c}\text { Shear } \\
\text { strength } \mathrm{t}_{0} \\
{[\mathrm{MPa}]}\end{array}$ & $\begin{array}{c}\text { Unit } \\
\text { weigth W } \\
{\left[\mathrm{kN} / \mathrm{m}^{3}\right]}\end{array}$ \\
\hline $\begin{array}{c}\text { Non-regular shape } \\
\text { and heterometric }\end{array}$ & 1050 & 350 & 1,8 & 0,1 & 0,032 & 19 \\
\hline $\begin{array}{c}\text { Roughly worked, not } \\
\text { perfectly rectangular }\end{array}$ & 1500 & 500 & 2,6 & 0,2 & 0,056 & 21 \\
\hline
\end{tabular}

As it is possible to note in Figure 8, several cracks have been surveyed on part of the aggregate not subject to restoration works: diagonal cracks and a vertical crack have been identified in particular on façade along South direction, induced by differential displacements occurred on masonry foundations.

According to methodology discussed in paragraph 1.2, computational models of aggregate, corresponding to configurations pre- and post-intervention respectively, have been implemented in 3DMacro computer code (Figure 9). 


\section{(a) Pre-intervention configuration}

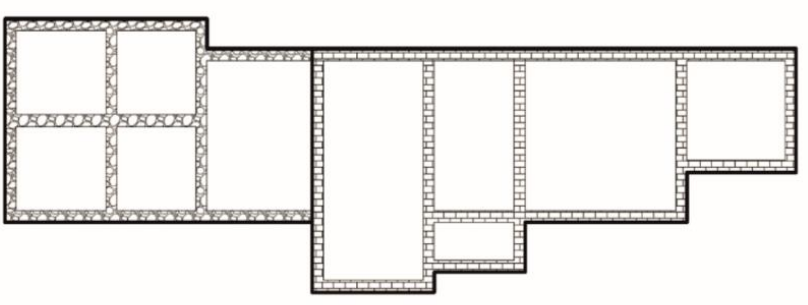

\section{Original configuration}

- Masonry stripe foundations

- Wooden beams and semi-rigid slab

\section{Building subject to restoration works}

(b) Post-intervention configuration

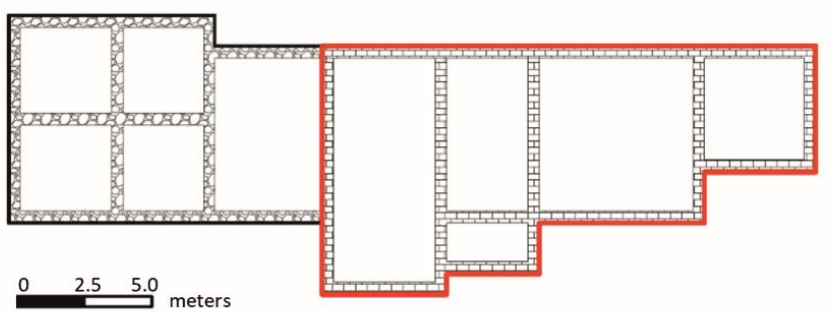

- Reinforced concrete beams as foundations

- Reinforced concrete slab

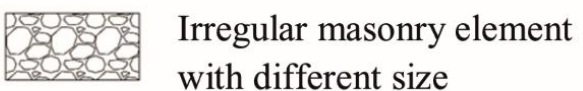

Regular masonry element

(c)

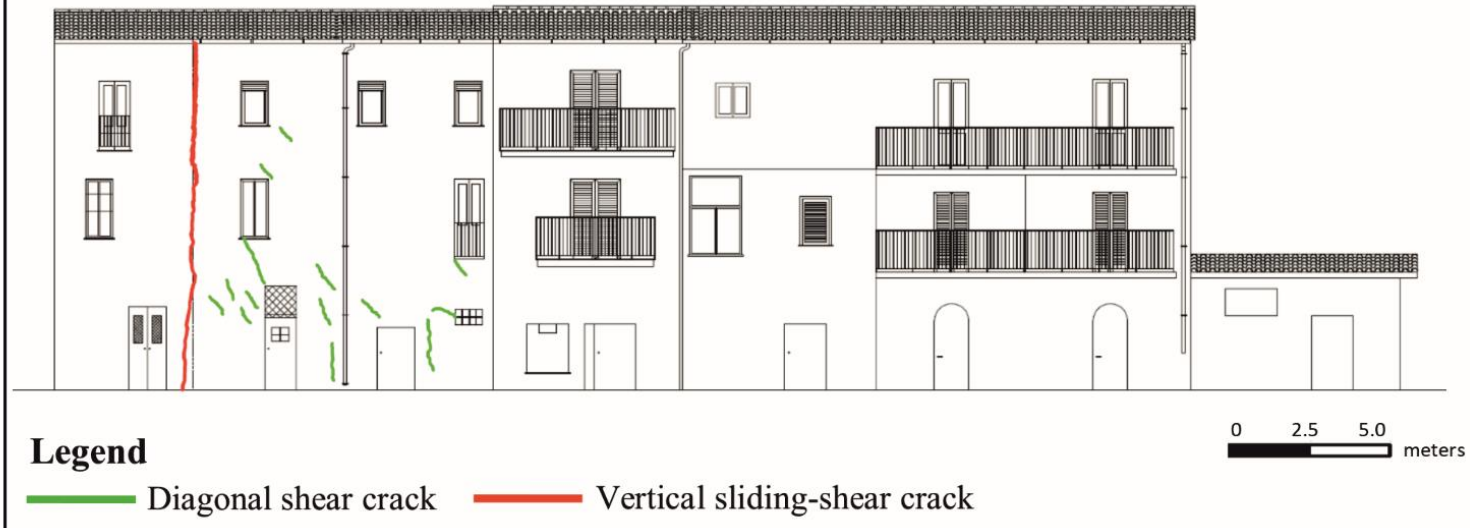

Figure 8. Schematic geometrical plan of load-bearing masonry walls in (a) pre- and (b) post-intervention configurations and (c) front view of the southern façade.

The cumulated vertical and horizontal displacement profiles measured at ground level along building façades by COSMO-SkyMed data at the end of each year in the period 2012-2016 have been progressively imposed to the foundations of both models and non-linear static analyses have been performed. The comparison of the results derived from the computational models affected by the same displacement profiles allowed to highlight a different behavior between the two configurations, as discussed in section 4.2 . 


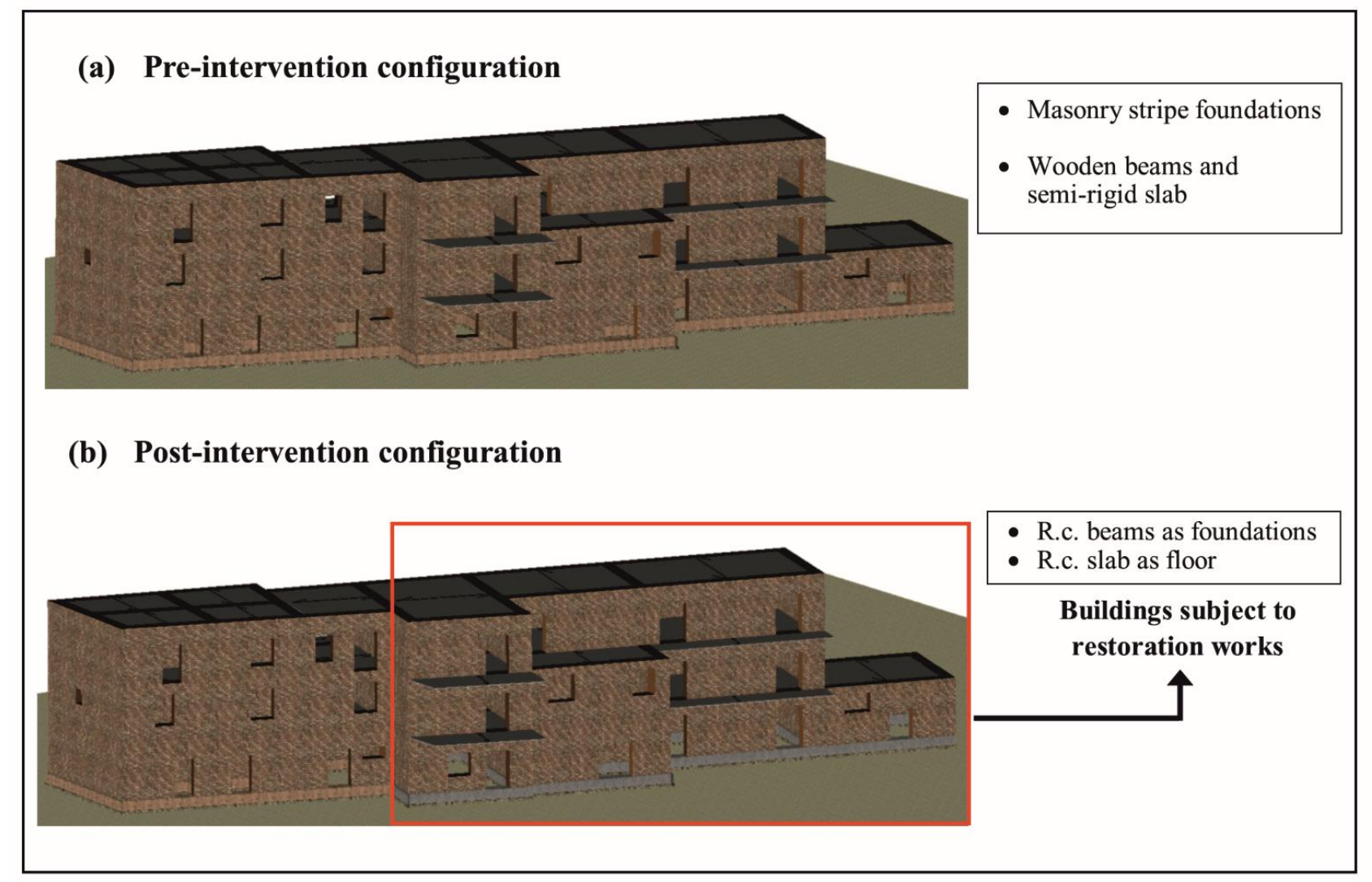

Figure 9. Axonometric views of the 3DMacro code computational models of buildings aggregate corresponding to (a) pre- and (b) post-restoration works configurations.

\section{Results and discussion}

\subsection{Assessment of interferometric products}

The behavior of the buildings before and after the intervention has been preliminary investigated by analyzing interferometric products: ENVISAT ASAR data allowed to define displacement time series of structures corresponding to configuration before restoration works, while COSMO-SkyMed products identified deformations in post-intervention configuration. Such analysis was made only for ascending data, since no persistent scatterers have been detected on the aggregate by ENVISAT ASAR descending dataset.

The analysis of the displacement time series of targets identified on each structure as representative of its deformation before and after the intervention (Figure 10) showed:

- a low increase of "LoS" displacement rate on a part of the aggregate not subject to restoration works; in detail, on this building, a mean displacement velocity of about $4 \mathrm{~mm} / \mathrm{yr}$ (target P1) was observed 
during the period 2002-2010, while a velocity of about $5 \mathrm{~mm} / \mathrm{yr}$ has been recorded during the period 2012-2016 (target P3);

- a significant decrease of the "LoS" displacement rate after the completion of the restoration works on the repaired part. The displacement velocity evolved from about $5 \mathrm{~mm} / \mathrm{yr}$ for the period 20022010 (target P2) to a mean displacement rate equal to $1 \mathrm{~mm} / \mathrm{yr}$ from 2012 (target P4).

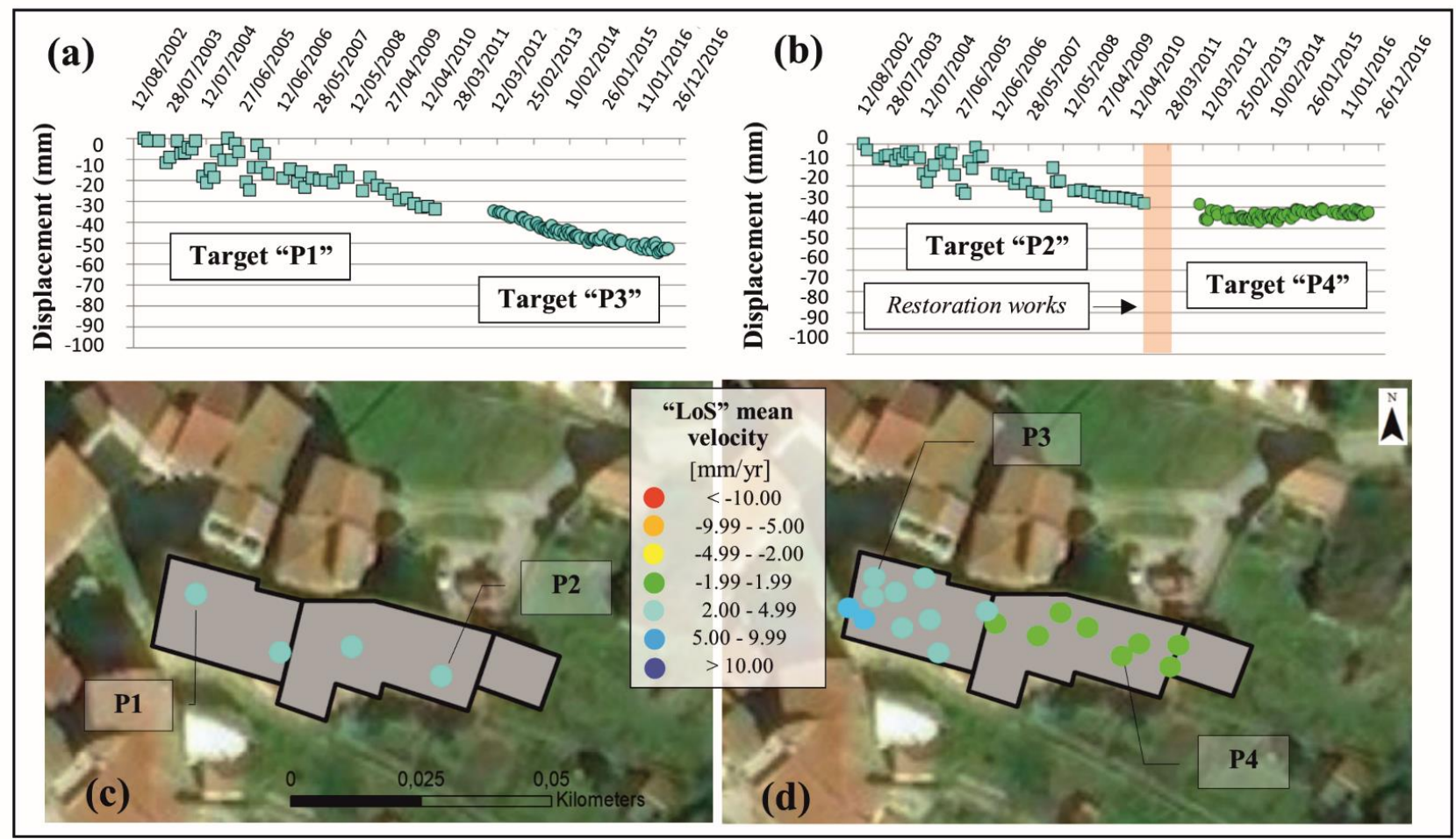

Figure 10. "LoS" displacement time series of targets identified on (a) the part of the aggregate not subject to restoration works and (b) on the repaired part. Square points identify measurements of ENVISAT ASAR satellite while circular points represent displacements recorded by COSMO-SkyMed constellation. The location of the selected targets P1 to P4 derived from ascending ENVISAT ASAR and COSMO-SkyMed data are shown in figures (c) and (d), respectively.

Subsequently, the availability of cumulated vertical and horizontal displacements obtained by COSMO-SkyMed products in the period 2012-2016 allowed to define the displacement gradient maps corresponding to post-intervention configuration: the gradient map calculates the maximum rate of change in displacement value from that cell to its neighbors, meant as rotation or slope in the change of a line joining two reference points and has enabled to identify the direction along which maximum vertical and horizontal differential displacements have occurred (Figure 11). 


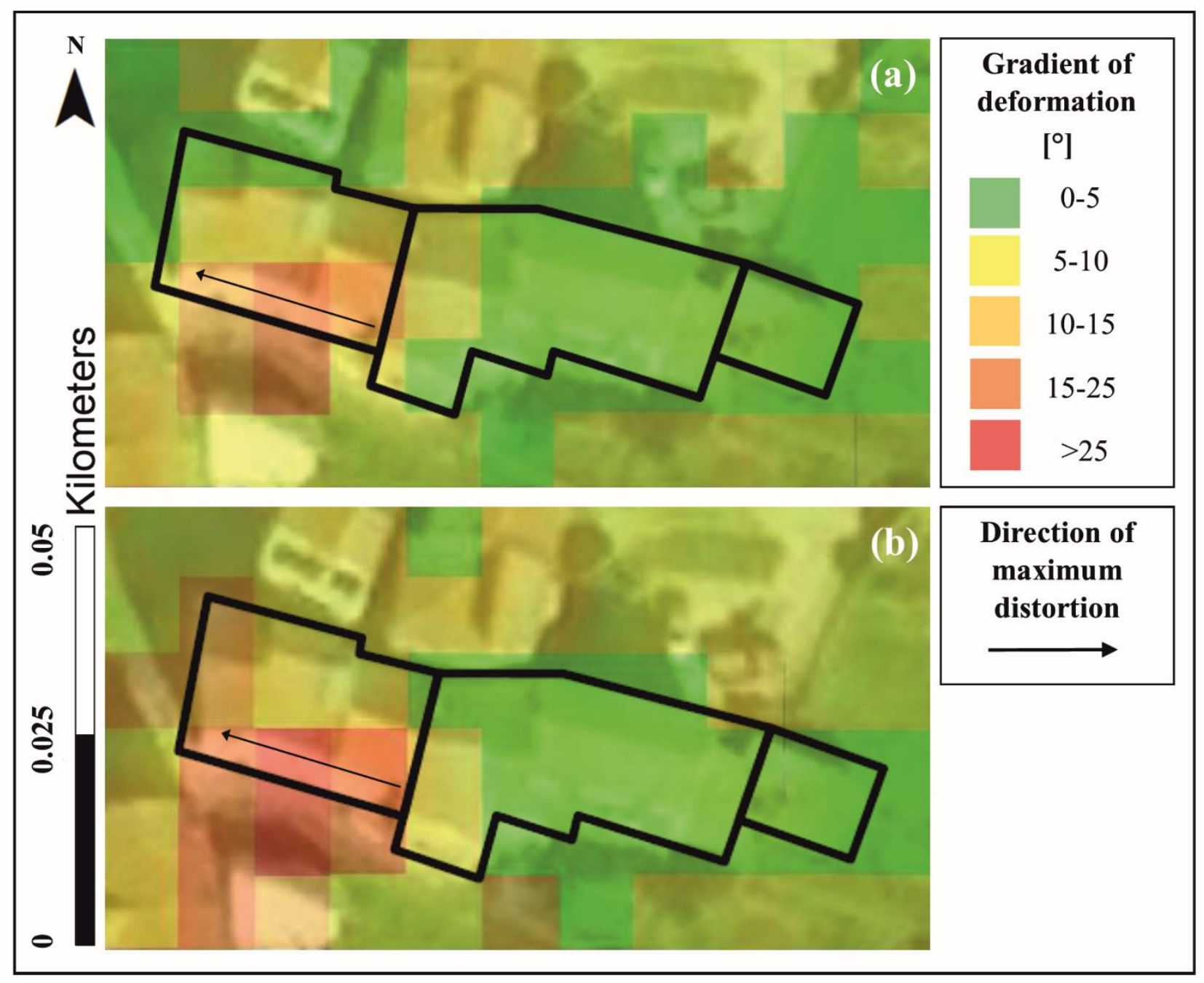

Figure 11. Displacement gradient maps along (a) vertical and (b) horizontal directions.

As can be seen in Figure 11, the consolidated structure subject to restoration works was affected by lower change in displacement value than that from the other part of the aggregate. According to the above-discussed results, the efficacy of remedial works to reduce the effects induced by the landslide on the superstructure has been confirmed.

Moreover, such analysis shows a good agreement between the direction of the maximum measured differential displacements and real distribution of damage surveyed in February 2017 on the South façade of the not repaired building (Figure 8c). This fact confirms that interferometric products represent a useful tool to investigate preliminary cause-effect relationships between maximum differential displacements and subsequent local failures of buildings, the latter induced either by landslide movements and by constructive factors (location of the structure, construction typology, foundation type, geometry, number of stories, etc.). 


\subsection{Numerical analyses}

As mentioned in section 2.2, the displacement profiles measured at ground level along the building façades in the period 2012-2016 have been progressively imposed to the foundations of computational models corresponding to pre- and post-restoration works configurations, as indicator of landslide action: in detail, starting from cumulated vertical and horizontal displacements at the end of each year in period 2012-2016 obtained by IDW interpolation, displacement profiles at ground surface in the surrounding areas near building façades (Figure 7c) have been applied to structure foundation level as external fixed loads and non-linear static analyses have been performed. Subsequently, to assess global performance of past and current models affected by the same displacement profiles, the number of masonry panels exhibiting elastic, yielding or fissuring conditions have been evaluated, thus highlighting a difference of behavior between both configurations of the structure (Figure 12).

Figure 12 shows an increase of masonry macro-elements exhibiting an elastic behavior and a decrease of number of panels yielded or fissured under each applied displacement profile after remedial works in the restored parts of the aggregate. On the other hand, this change is less evident on building not subject to remedial interventions. This fact confirms the efficacy of the consolidation works to improve the performance of the structure within a landslide-affected area.

Furthermore, the numerical analyses performed by means of structural models also allowed to investigate tensional state of each panel due to cumulated displacement profiles during the considered period and to identify portions of masonry walls where the main collapse mechanisms occur.

In particular, a good correspondence between the distribution and typology of cracks predicted by the computational model considering the DInSAR displacements occurred during the period 2012-2016 and the real damage surveyed in February 2017 is observed in Figure 13 for the non-restored building. Such level of analysis allowed to investigate the cause of occurrence of a vertical sliding-shear crack and some diagonal-shear cracks on the south façade of the non-consolidated building. These cracks have been induced by differential displacements occurred on the foundations of the masonry building and subsequently by a rotational settlement on a part of the load-bearing wall. Such effect has been 
confirmed by analyzing vertical crack whose width increases from bottom to top along façade. On the repaired building instead, no cracks have been surveyed since the reinforced concrete foundation beams and the reinforced floors concrete slab have considerably increased global stiffness of the structure, thus reducing stresses and distortions induced by ground movements.

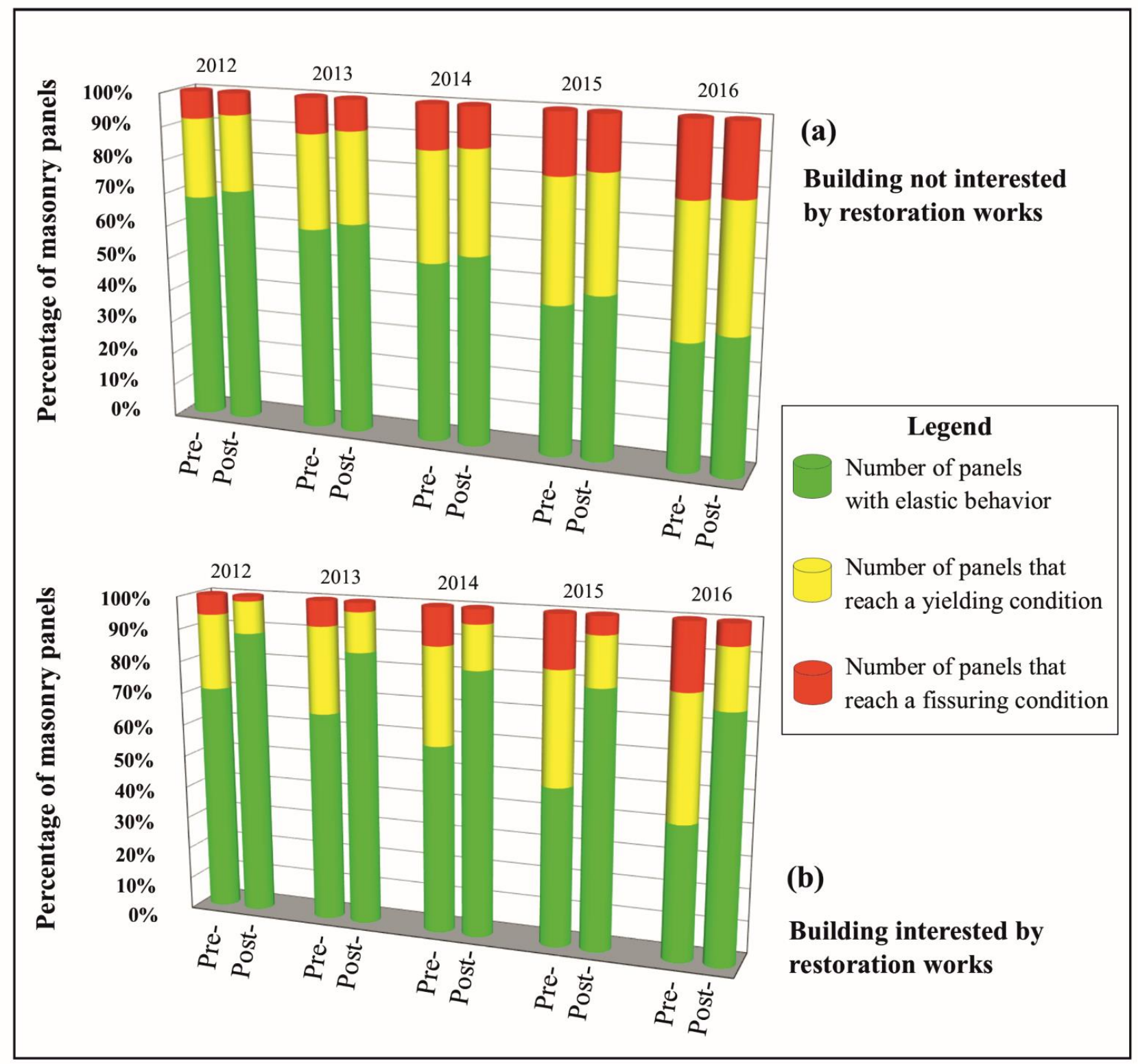

Figure 12. Comparison of results obtained from the numerical analyses performed by computational models corresponding to pre- and post-restoration works configurations: (a) on the non-consolidated and (b) on the consolidated parts of the aggregate. 


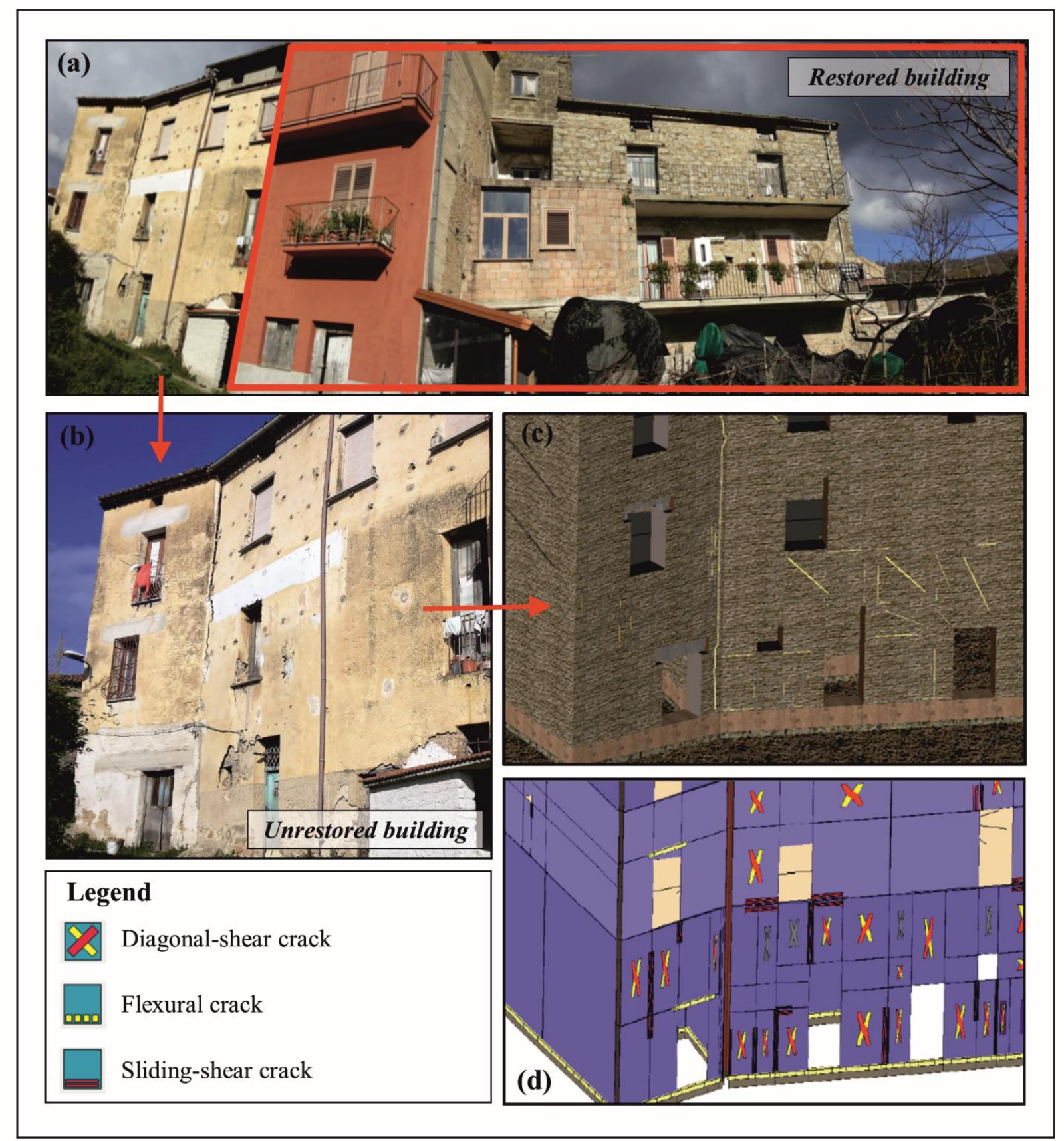

Figure 13. (a) General view of the damaged buildings aggregate. (b) Detailed view of the unrestored building taken during the in-situ campaign in February 2017; (c) computational and (d) numerical 3D model of the unrestored building with predicted damage carried out on the south façade.

\section{Conclusions}

In this work an integrated approach exploiting DInSAR data and numerical analyses to investigate the behavior of buildings in landslide-affected area is proposed. Although benefits of DInSAR to monitor ground instability phenomena are widely known, this work has demonstrated that DInSAR 
technique also represents a helpful support for the assessment of the effects of landslides on exposed facilities.

A general framework and scale-specific procedure tailored for the use of interferometric products in the study of building performance in urban areas affected by slow-moving landslides is described in detail and illustrated trough a specific case of study located in Moio della Civitella (Italy).

The selected case of study is a masonry buildings aggregate, whose structures exhibit different deformational behaviors and for which the efficacy of restoration works developed in 2010 have been assessed through the combined use of ENVISAT ASAR and COSMO-SkyMed datasets. As it is well known, the use of COSMO-SkyMed data significantly improved the level of detail of the analysis on man-made structures due to its higher resolution, since many targets show up on roofs and façades. Therefore, DInSAR high resolution data were interpolated using IDW method to provide continuous maps of the measured displacements. The high density of persistent scatterers located on buildings and in the surrounding area ensures that the performed IDW interpolation process has introduced a low level of uncertainties in the assessment of continuous displacements. This information allowed to investigate horizontal and vertical differential displacement of single parts of the aggregate, identifying the prevalent direction of deformation. The availability of high resolution COSMOSkyMed PSs allowed to provide not only the measurement of the landslide intensity, but also precise information about building deformation, as indicator of their response to ground displacements. Structural performance is dependent, as confirmed by this work, by basic constructive factors, such as building typology, foundation type, number of stories, geometry, properties of materials, etc. A more detailed PS analysis thus highlights the difference of building behavior, according to the abovementioned different structural properties.

DInSAR displacement time-series of targets corresponding to pre- and post-intervention configurations also confirmed the efficacy of restoration works on the repaired part of the studied aggregate, highlighting the usefulness of DInSAR for monitoring consolidated structures. 
Subsequently, structural analyses performed with a numerical code on computational models corresponding to the original and current configurations have permitted to identify the most affected zones of the aggregate, providing detailed information about the type of damage affecting the structures, including their distribution and typology.

Thanks to a validation process based on in situ observations, the results of the analyses showed the capability of the proposed approach to pursue goals commensurate to the analysis scale, to better detect and interpret the underlying phenomena and their consequences (i.e. the ground instabilities and their influence on building deformations and damage).

The cross-comparison of DInSAR and structural data with local failures and damage observed in situ allowed a validation of radar data, to achieve a complete analysis which can be particularly useful for strategies of building management.

As a conclusion, it can be said that such approach, combining DInSAR products and structural background data represents a powerful tool for complementing classic forensic analysis of buildings performed by means of field observations and in situ records providing a more detailed local vision of the problem.

\section{Acknowledgment}

Research funded by the Campania Region through Regional Law n. 5/2002, year 2008 - Project "La pericolosità delle frane intermittenti in formazioni strutturalmente complesse; analisi comparata dei parametri geologici, mineralogici e geotecnici” (CUP_E64G08000060002)- Scientific manager: prof. Domenico Calcaterra.

Part of this work was partially supported by the Spanish Ministry of Economy, Industry and Competitiveness (MINECO), the State Agency of Research (AEI) and the European Funds for Regional Development (FEDER) under projects TEC2017-85244-C2-1-P and TIN2014-55413-C22-P and the Spanish Ministry of Education, Culture and Sport under project PRX17/00439.

The authors are also grateful to the precious support given by the anonymous reviewers for their valuable observations and suggestions to improve the quality of the paper 


\section{References}

1. Guzzetti F, Carrara A, Cardinali M, Reichenbach P. Landslide hazard evaluation: a review of current techniques and their application in a multi-scale study, Central Italy. Geomorphology, 31, 1999; 181-216.

2. Guzzetti F, Mondini AC, Cardinali M, Fiorucci F, Santangelo M, Chang KT. Landslide inventory maps: new tools for an old problem. Earth-Sci. Rev, 112, 2012; 42-66.

3. Ciampalini A, Bardi F, Bianchini S, Frodella W, Del Ventisette C, Moretti S, and Casagli N. analysis of building deformation in landslide area using multisensor PSInSAR ${ }^{\mathrm{TM}}$ technique. International Journal of Applied Earth Observation and Geoinformation, 33, 2014; 166-180.

4. Fuchs S. Susceptibility versus resilience to mountain hazards in Austria. Paradigms of vulnerability revisited. Natural Hazards and Earth System Sciences, 9 (2), 2009; 337-352.

5. Pitilakis K, Fotopoulou SD. Fragility curves for reinforced concrete buildings to seismically triggered slow-moving slides. Soil Dynamics and Earthquake Engineering, 2013; 143-161.

6. Corominas J, van Westen C, Frattini P, Cascini L, Malet JP, Fotopoulou S, Catani F, Van Den Eeckhaut M, Mavrouli O, Agliardi F, Pitilakis K, Winter MG, Pastor M, Ferlisi S, Tofani V, Hervás J, Smith JT. Recommendations for the quantitative analysis of landslide risk. Bull. Eng. Geol. Environ. 73 (2), 2014; 209-263.

7. Mavrouli O, Fotopoulou S, Pitilakis K, Zuccaro G, Corominas J, Santo A, Cacace F, De Gregorio D, Di Crescenzo G, Foerster E, Ulrich T. Vulnerability assessment for reinforced concrete buildings exposed to landslides. Bulletin of Engineering Geology and the Environment, 73, 2014; $265-289$.

8. Peduto D, Pisciotta G, Nicodemo G, Arena L, Ferlisi S, Gullà G, Borrelli L, Fornaro G, Reale D. A procedure for the analysis of building vulnerability to slow-moving landslides. In: Daponte P, Simonelli AL, editors. Proc. of the 1st IMEKO TC4 International Workshop on Metrology for Geotechnics, Benevento, Italy, March 17-18, 2016. Red Hook, NY 12571, USA: Curran Associates Inc; 2016, p. 248-254.

9. Tomás R, García-Barba J, Cano M, Sanabria MP, Ivorra S., Duro J., Herrera G. Subsidence damage assessment of a Gothic church using differential interferometry and field data. Structural Health Monitoring, 2012; 751-762.

10. Cascini L, Peduto D, Reale D, Arena L, Ferlisi S, Verde S, Fornaro G. Detection and monitoring of facilities exposed to subsidence phenomena via past and current generation SAR sensors. Journal of Geophysics and Engineering 2013;10(6), article number 064001, 14 p. https://doi.org/10.1088/1742-2132/10/6/06400 
11. Bianchini S, Tapete D, Ciampalini A, Di Traglia F, Del Ventisette C, Moretti S, and Casagli N. Multi-temporal evaluation of landslide-induced movements and damage assessment in San Fratello (Italy) by means of C-and X-band PSI data. Mathematics of Planet Earth, 2014; 257261.

12. Huang Yu, Miao Yu, Qiang Xu, Sawada Kazuhide, Moriguchi Shuji, Yashima Atsushi, Liu Chengwei, Xue Long. InSAR-derived digital elevation models for terrain change analysis of earthquake-triggered flow-like landslides based on ALOS/PALSAR imagery. Environmental Earth Sciences, 73(11), 2015; 7661-7668.

13. Infante D, Confuorto P, Di Martire D, Ramondini M, Calcaterra D. Use of DInSAR data for multilevel vulnerability assessment of urban settings affected by slow-moving and intermittent landslides. Procedia Engineering, 158, 2016; 470- 475.

14. Infante D, Di Martire D, Confuorto P, Ramondini M, Calcaterra D, Tomàs R, Centolanza G, Duro J. Multi-temporal assessment of building damage on a landslide-affected area by interferometric data. Research and Technologies for Society and Industry (RTSI), IEEE 3rd International Forum, 2017; 1-6.

15. Peduto D, Ferlisi S, Nicodemo G, Reale D, Pisciotta G, Gullà G. Empirical fragility and vulnerability curves for buildings exposed to slow-moving landslides at medium and large scales. Landslides 2017;14(6):1993-2007. https://doi.org/10.1007/s10346-017-0826-7

16. Arangio S, Calò F, Di Mauro M, Bonano M, Marsella M, Manunta M. An application of the SBAS-DInSAR technique for the assessment of structural damage in the city of Rome. Structure and Infrastructure Engineering: Maintenance, Management, Life-Cycle Design and Performance, 2013; 1469-1483.

17. Ferlisi S, Peduto D, Gullà G, Nicodemo G, Borrelli L, Fornaro G. The use of DInSAR data for the analysis of building damage induced by slow-moving landslides. In: Lollino G, Giordan D, Crosta GB, Corominas J, Azzam R, Wasowski J, Sciarra N, editors. Engineering Geology for Society and Territory. Cham: Springer International Publishing Switzerland; 2015, Vol. 2, p. 1835-1839. https://doi.org/10.1007/978-3-319-09057-3_325

18. Tessari G, Cerchiello V, Velterop E, Riccardi P, De Filippi M, Pasquali P. Risk of building damage by modelling interferometric time series. International Geoscience and Remote Sensing Symposium, 2016; 7334-7337.

19. Cuevas M, Crosetto M, Monserrat O. Monitoring urban deformation phenomena using satellite images. 9th International Geomatic Week, 2011. 
20. Tessitore S, Di Martire D, Calcaterra D, Infante D, Ramondini M, Russo G. Multitemporal synthetic aperture radar for bridges monitoring, Proceedings of SPIE - The International Society for Optical Engineering, 10431, 2017.

21. Berardino P, Fornaro G, Lanari R, Sansosti E. A new algorithm for surface deformation monitoring based on small baseline differential SAR interferograms. IEEE Transactions on Geoscience and Remote Sensing, 40(11), 2002; 2375-2383.

22. Ferretti A, Fumagalli A, Novali F, Prati C, Rocca F, Rucci A. A new algorithm for processing interferometric data-stacks: SqueeSAR. IEEE Transactions on Geoscience and Remote Sensing, 49(9), 2011; 3460-3470.

23. Sowter A, Bateson L, Strange P, Ambrose K, Syafiudin MF. DInSAR estimation of land motion using intermittent coherence with application to the South Derbyshire and Leicestershire coalfields. Remote Sensing Letters, 4, 2013; 979-987.

24. Gruppo Sismica. 3DMacro il software per le murature (3D computer program for the seismic assessment of masonry buildings). 2014.

25. Mora O, Mallorquí JJ, Broquetas A. Linear and non-linear terrain deformation maps from a reduced set of interferometric SAR images. IEEE Transactions on Geoscience and Remote Sensing, 41, 2003; 2243-2253.

26. Cascini L, Fornaro G, Peduto D. Advanced low- and full-resolution DInSAR map generation for slow-moving landslide analysis at different scales. Engineering Geology, 112, 2010; 29-42.

27. Di Martire D, De Luca G, Ramondini M, Calcaterra D. Landslide-related PS data interpretation by means of different techniques. Landslide Science and Practice, 2013; 347-355.

28. Burland JB \& Wroth CP. Settlement of buildings and associated damage. Settlement of Structures, $1974 ; 611-654$.

29. Bianchini S, Pratesi F, Nolesini T, and Casagli N. Building deformation assessment by means of persistent scatterer interferometry analysis on a landslide-affected area: The Volterra (Italy) case study. Remote Sensing 7, 2015; 4678-4701.

30. Boscardin MD \& Cording EJ. Building response to excavation-induced settlement. Journal of Geotechnical Engineering, 115(1), 1989; 1-21.

31. Caliò I, Marletta M, Pantò B. A new discrete element model for the evaluation of the seismic behaviour of unreinforced masonry buildings. Engineering Structures, 40, 2012; 327-338.

32. Caliò I, Marletta M, Pantò B. A simplified model for the evaluation of the seismic behavior of masonry buildings. Proceeding of the 10th International Conference on Civil, Structural and Environmental Engineering Computing, 2005. 
33. Turnšek V \& Čačovič F. Some experimental results on the strength of brick masonry walls. In: West HWH, Speed KH, editors. Proc of the 2nd International Brick Masonry Conference, Stokeon-Trent (England), 12-15 April 1970. Stoke-on-Trent: British Ceramic Research Association; 1971, p 149-156.

34. Bonardi G, D’Argenio B, and Perrone V. Carta geologica dell'Appennino Meridionale. 74th Congresso della Società Geologica d'Italia, 1988.

35. Esu F. Behavior of slopes in structurally complex formations. International Symposium on the Geotechnics of Structurally Complex Formations, 1977; 292-304.

36. Calò F. Analysis of slow-moving landslides in Southern Apennines by integrating ground monitoring and Remote Sensing techniques. PhD Thesis, 2009.

37. Calcaterra D, Ramondini M, Calò F, Longobardi V, Parise M, Galzerano CM. DInSAR techniques for monitoring slow moving-landslides. Landslides and engineered slopes. From the Past to the Future. Proc. of the Tenth Int. Symp. on landslides and engineered slopes, 2008; 1089-1094.

38. Bedient PB \& Huber WC. Hydrology and floodplain analysis, 2nd edn. Addison-Wesley, 1992; $692 \mathrm{p}$.

39. Di Martire D, Ramondini M, Calcaterra D. Integrated monitoring network for the hazard assessment of slow-moving landslides at Moio della Civitella (Italy). Rendiconti Online Società Geologica Italiana, 35, 2015; 109-112.

40. Infante D. Integrated analysis of building vulnerability in urban areas affected by slow-moving, intermittent landslides using SAR Interferometry. PhD Thesis, 2018. 